ECCOMAS

Proceedia
COMPDYN 2021

$8^{\text {th }}$ ECCOMAS Thematic Conference on Computational Methods in Structural Dynamics and Earthquake Engineering M. Papadrakakis, M. Fragiadakis (eds.)

\title{
FRAGILITY MODELS FOR EXISTING MASONRY INFILLED RC FRAMES IN THE EMILIA AREA
}

\author{
G. Salamida ${ }^{1}$, N. Buratti ${ }^{2}$ \\ ${ }^{1}$ CIRI - Edilizia e Costruzioni (University of Bologna) \\ Via del Lazzaretto 15/5, Bologna \\ e-mail: gianluca.salamida2@unibo.it \\ 2 DICAM (University of Bologna) \\ Viale Risorgimento 2, Bologna \\ nicola.buratti@unibo.it
}

\begin{abstract}
Fragility models are important tools for seismic risk assessment and seismic damage scenarios estimation. Some models are already available in the literature, however, in the case of infilled $R C$ frames, further investigations are necessary, given the high uncertainty about their behaviour. In fact, damage observations following seismic events, suggest that the presence of masonry infills can strongly influence the response of reinforced concrete $(R C)$ frames and affect their collapse mechanisms. The main goal of this work is to contribute to the seismic vulnerability assessment of the existing building stock in the Emilia-Romagna region in northern Italy, developing fragility models for infilled $R C$ frame buildings. On the basis of an analysis of both census data on the existing building stock and on damage survey forms after the 2012 Earthquake, a set of representative structures was defined and modelled with finite elements, adopting a concentrated plasticity approach. Different modelling approaches of the infill walls were considered, using single and multi-strut models, in order to simulate shear failure in columns. Non-linear static (push-over) analyses were then carried out on these models to obtain their capacity curves. Displacement demands were computed using simplified procedures (IN2 method). The definition of damage levels in the models was based on the achievement of local deformation capacity limits of structural and non-structural elements, according to the classification provided by the EMS-98 Macro-seismic scale. Fragility curves were finally obtained by considering uncertainties in material properties, by means of the Response Surface method, as well as ground-motion record-to-record variability.
\end{abstract}

Keywords: RC frames, masonry infills, fragility curves, pushover analysis, seismic fragility. 


\section{INTRODUCTION}

Many of the buildings currently present in the European area date back to several decades ago and were built without seismic design criteria, due to changes in the seismic classification of the territory and to the considerable evolution of structural design codes in the most recent years; hence the interest and the need for studies on existing buildings. Within a probabilistic framework, an important tool for assessing the seismic vulnerability of existing buildings are fragility curves, which associate the probability of exceeding a certain damage level to different levels of a certain measure of ground-motion intensity.

After the Emilia earthquake (northern Italy) in May 2012, many of the studies on existing buildings focused on masonry buildings [1] and prefabricated structures [2,3], i.e. the types on which the most severe damage was observed. Studies have also been carried out on reinforced concrete frames with masonry infills [4]; in particular, fragility curves have been developed in [5], for some models of representative buildings, based on capacity limits associated with the damage levels defined by the EMS-98 macro-seismic scale. Furthermore, this study provided a damage scenario for the area hit by the Emilia earthquake, also making predictions on the cumulative damage caused by multiple seismic events. The typical damage observed following seismic events raises the need to use models capable of describing the local interaction phenomena between frames and infill panels $[6,7]$. Preventive considerations are necessary on the choice of materials characteristics, with particular attention to the masonry infill properties, which can strongly influence the structural behaviour of the building and, consequently, the assessment of its vulnerability [8].

The present work presents the fragility curves for existing residential Reinforced Concrete (RC) frame structures with masonry infills, and is part of a larger study aimed at assessing the seismic vulnerability of the existing building heritage in the Emilia area. These fragility curves are obtained analysing, by means of nonlinear static analyses and Response Surface metamodels [9], a series of case study structures, which in terms of geometry, dimensions and mechanical characteristics, can be considered representative of the fraction of the existing building stock under study.

\section{REFERENCE BUILDINGS}

\subsection{Characteristics of the building stock}

In order to define the case study buildings, preliminary investigations were made to acquire information about the main characteristics of the existing building stock: in particular, reference was made to the data of the AEDES forms (i.e. post-earthquake damage evaluation forms used in Italy), compiled following the Emilia earthquakes, occurred in May 2012, and census data provided by ISTAT (National Institute of Statistics), from the 15th general population and housing census, for the areas of Bologna, Ferrara and Modena. Analysing the available data on existing buildings, once the construction type and intended use of interest have been identified, all data was filtered by construction period, number of storeys, average floor surface and regularity.

The data from the AEDES forms and census, restricted to RC frame structures for residential use, involve sample consisting of 1573 and 58980 buildings, respectively: it is clear that the census data offer a broader and more general vision than the AEDES data, which instead concern a small part of the building stock, as they are compiled only for a subset of the buildings affected by the earthquake, i.e., in general, for buildings that have shown some damage. On the other hand, AEDES data can provide important information of the structural features of the 
buildings that were most susceptible to damage. Figure 1 shows the distribution of the number of floors in the dataset.

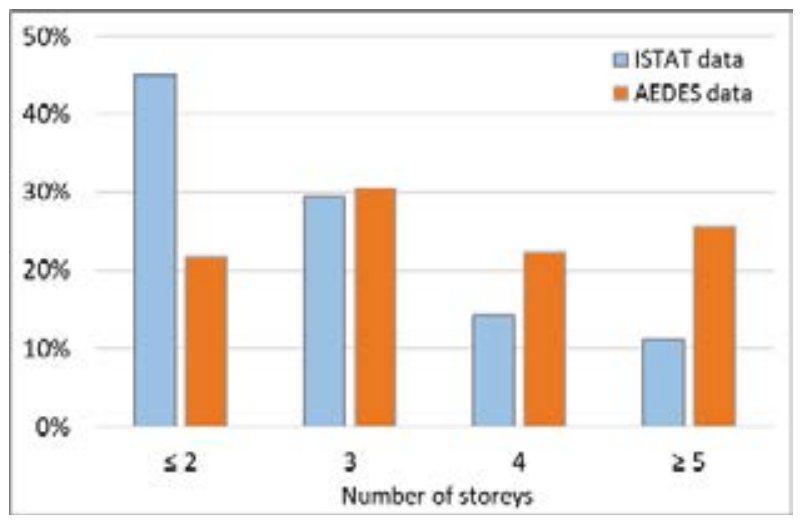

Figure 1: Number of storeys of existing building stock.

There is a clear prevalence of low-rise buildings, with less than 2 floors, for the ISTAT data, in contrast to the AEDES forms data, which show an opposite trend for buildings with a greater number of floors (in detail 4 or greater than or equal to 5): this can suggests that, in general, buildings with a higher number of floors, although they constitute a smaller percentage of the building stock, also constitute the most fragile part. According to ISTAT data, almost $58 \%$ of the RC frame structures were built between the $50 \mathrm{~s}$ and $70 \mathrm{~s}$, a time period characterized the complete lack of seismic design criteria in the area affected by the 2012 earthquake.

For the definition of the geometry in plan and elevation of the models to be studied, the data on the average floor surface was analysed and correlated with the number of floors (as shown in Figure 2). It should be noticed that only the AEDES forms provide this data. The range of floor areas between $100 \mathrm{~m}^{2}$ and $170 \mathrm{~m}^{2}$ is common for buildings with a low number of floors, while it is not very frequent in buildings with 5 or more floors. The range of surfaces between 170 and $300 \mathrm{~m}^{2}$ characterizes a large part of the sample of buildings, being present in a relatively high percentage in all categories based on the number of floors (between $23.7 \%$ and $39.2 \%$ ), in particular for structures with a number of floors equal to or greater than 4 . Floor areas from 300 to $500 \mathrm{~m}^{2}$ mainly characterize buildings with a number of floors greater than or equal to 4 .

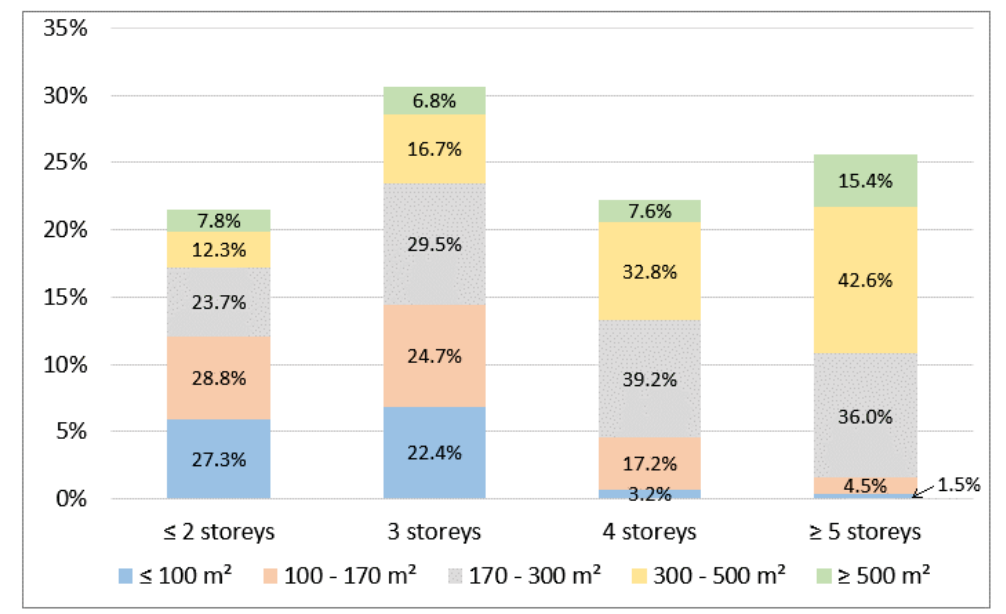

Figure 2: Average floor area and number of storeys (AEDES data).

It should be specified that the relationship between the average floor area and the number of floors may not fully represent the actual building stock, but only a subset of it, as only the 
AEDES forms makes this information available. However, as specified above, it can be thought that these data provide more direct information on the most fragile part of the building stock and is therefore of greatest interest in the context of assessing the seismic vulnerability of existing buildings.

\subsection{Definition of case study structures}

On the basis of the characteristics observed, two types of building were defined: in particular a 2-storey and a 4-storey building. The plan surface area of each building (see Table 1) was chosen in such a way as to obtain structures that are as representative as possible of the existing stock.

In order to conduct non-linear static analyses, two-dimensional models were created. However, since the existing buildings in the area under consideration often feature frames with different features in different horizontal directions, two models were considered for each structure. The direction indicated with $\mathrm{X}$ corresponds to the one of main frames, while $\mathrm{Y}$ corresponds to the one of slabs, which are assumed as one-way.

\begin{tabular}{|c|c|c|c|c|c|c|c|}
\cline { 2 - 6 } \multicolumn{1}{c|}{} & \multicolumn{3}{c|}{ X direction } & \multicolumn{3}{c|}{ Y direction } & \\
\hline MODEL & $\mathbf{n}^{\circ}$ bays & $\begin{array}{c}\text { span length } \\
{[\mathbf{m}]}\end{array}$ & $\mathbf{L x}[\mathbf{m}]$ & $\mathbf{n}^{\circ}$ bays & span length $[\mathbf{m}]$ & $\mathbf{L y}[\mathbf{m}]$ & $\begin{array}{c}\text { Plan surface } \\
{\left[\mathbf{m}^{2}\right]}\end{array}$ \\
\hline 2 storey & 3 & 4.5 & 13.5 & 3 & 4 & 12 & 162 \\
\hline 4 storey & 4 & 4.5 & 18 & 3 & 4 & 12 & 216 \\
\hline
\end{tabular}

Table 1: Main geometric features of benchmark buildings.

\subsection{Simulated design}

A simulated design was carried out on the reference buildings, to define the size of the crosssections of the structural elements and the relative reinforcements. To this purpose, it is of primary importance to place the buildings in an appropriate regulatory context. Based on the ISTAT census data on the construction period for the sample of buildings analysed, it is believed that the period of greatest interest, spans from the 50 s to the $70 \mathrm{~s}$.

In the simulated design of the structures, the method of admissible stresses was used, respecting the requirements set out in the Italian structural design code issued in 1976 [10], thus considering it the reference standard. All the structures have been designed for vertical loads only; unlike the perimeter beams, shallow wide beams were considered for the internal frames, a typical solution of residential buildings, in which, due to architectural requirements, the thickness of beams is maintained within the thickness of slabs. Permanent loads were assumed equal to $5 \mathrm{kN} / \mathrm{m}^{2}$ while live loads to $2 \mathrm{kN} / \mathrm{m}^{2}$. A concrete with a characteristic compressive strength $\mathrm{R}_{\mathrm{ck}}$ equal to $25 \mathrm{MPa}$ was considered for the simulated design. For the characterization of the reinforcing bars, reference was made to a series of studies on the mechanical characteristics of the steels used in RC structures in the 1960s [11]: in particular, smooth bars were used, with a median yield stress equal to $369.9 \mathrm{MPa}$, which lead to an allowable stress of $155 \mathrm{MPa}$. The stirrup spacing in columns is assumed equal to $25 \mathrm{~cm}$. The size of columns depends on their axial stress, evaluated on the basis of tributary areas, while the beams were designed only for the bending moment due to the vertical loads. In particular, the perimeter beams have a section with dimensions $30 \times 50 \mathrm{~cm}$, while the cross-section of roof beams are $30 \times 45 \mathrm{~cm}$. The internal main beams have a section of $75 \times 24 \mathrm{~cm}$. Secondary beams, i.e. in the $\mathrm{Y}$ direction, are also considered, but of reduced dimensions. 


\section{MODELLING}

The case study buildings must be schematized in a finite element model that is able to simulate the nonlinear structural response under to horizontal loads, both for structural elements (beams and columns) and non-structural elements, such as masonry infills. An approach based on lumped plasticity was adopted in the modelling. Finite element modelling was carried out through the OpenSees software [12]. The model of each structure was not limited only to one infilled frame (external frame), but involved the modelling of two frames side by side (Figure 3): one infilled and one bare frame, bound to undergo the same floor displacements, under a rigid diaphragm assumption.

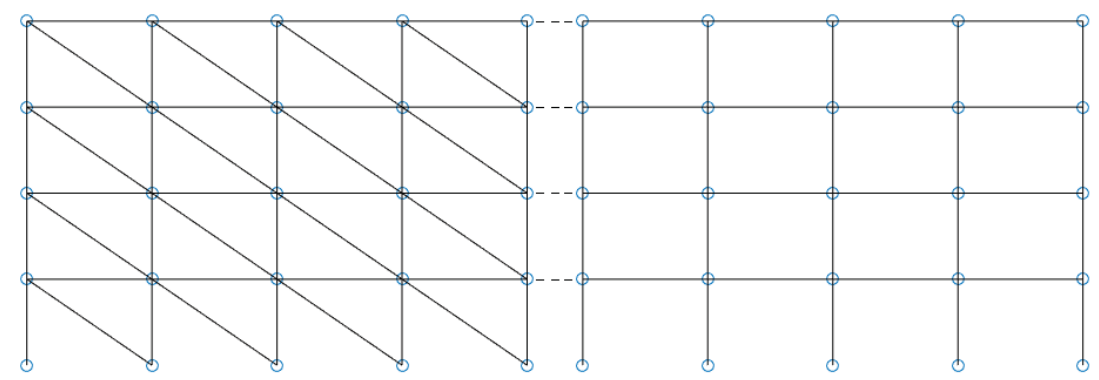

Figure 3: Example of the adopted modelling scheme.

\subsection{Frame elements}

The frame elements (beams and columns) have been modelled using linear elastic elements, with rotational springs at their ends (ZeroLength elements). A moment-rotation relationship characterized by a three-linear envelope was adopted, defined by three characteristic points, which represent the yield condition, the ultimate condition, and the complete loss of strength. the latter is defined by the slope of the degrading branch, until zero moment, based on the Ibarra, Medina and Krawinkler model [13]. For each hinge the rotation capacity, corresponding to the yield $\left(\theta_{y, s}\right)$ and ultimate $\left(\theta_{u, s}\right)$ conditions was evaluated based on the approach suggested by Eurocode 1998-part 3 [14] for estimating the yield $\left(\theta_{y}\right)$ and ultimate $\left(\theta_{u}\right)$ chord rotations of RC members:

$$
\begin{gathered}
\theta_{y}=\emptyset_{y} \frac{L_{v}+a_{v} z}{3}+0.0014\left(1+1.5 \frac{h}{L_{v}}\right)+\frac{\varepsilon_{y}}{d-d^{\prime}} \frac{d_{b l} f_{y}}{6 \sqrt{f_{c}}} \\
\theta_{u}=\frac{1}{\gamma_{e l}} 0.016\left(0.3^{v}\right)\left[\frac{\max \left(0.01 ; \omega^{\prime}\right)}{\max (0.01 ; \omega)} f_{c}\right]^{0.225}\left(\min \left(9 ; \frac{L_{v}}{h}\right)\right)^{0.35} 25^{\alpha \rho_{s x}} f_{\frac{f_{w}}{f_{c}}}\left(1.25^{100 \rho_{d}}\right)
\end{gathered}
$$

where $\phi_{\mathrm{y}}$ is the yield curvature of the element cross-section, $L_{v}$ is the shear span length, $h$ is the cross-section depth; $\omega$ and $\omega^{\prime}$ are, respectively, the mechanical reinforcement ratio of the tension and compression longitudinal bars; $f_{c}, f_{y}$ and $f_{y w}$ are the concrete compressive strength, the longitudinal reinforcement yield tension and the stirrup yield tension, respectively, (MPa); $\varepsilon_{y}$ is the steel elastic modulus; $d_{b l}$ is the mean diameter of longitudinal tension reinforcement; $d$ and $d^{\prime}$ are the depths to the tension and compression reinforcement, respectively; $z$ is the internal lever arm length and $a_{v}$ is equal to 1.0 if shear cracking is expect to precede the end section flexural yielding and it is equal to 0 otherwise; $\rho_{s x}$ is the ratio of transverse reinforcement in loading direction $(\mathrm{x}) ; \rho_{d}$ is the diagonal reinforcement ratio; $\alpha$ is the confinement effectiveness ratio; $\gamma_{e l}$ is equal to 1.5 for primary seismic elements and it is equal to 1.0 otherwise; $v$ is the normalized axial force. 
Some of the parameters in Eqns. 1 and 2 are not constant during a pushover analysis, however, given the limited number of storeys of the case study buildings, the axial force in the columns was assumed as constant, and due to non-seismic gravitational loads only. The shear span length $L_{v}$ was defined on the basis of some preliminary analyses that led to the choice of the following values: half the length of the element for beams and columns, with the exception of the first storey columns, for which a point of contraflexure placed at $2 / 3$ of the length, starting from the base, was assumed. Values of $\theta_{y}$ and $\theta_{u m}$ were corrected, according to Eurocode 1998part 3 rules, in order to consider lapping of reinforcing bars, the presence of smooth bars and the lack of seismic details.

In modelling the beam-spring assembly, the flexural behaviour of each element of the frame has been traced back to that of two equivalent cantilever beams. The effective moment-rotation relationship for the rotational springs was defined by subtracting from the total chord rotation (beam-spring system) the chord rotation due to the elastic deformation of the element, as reported below:

$$
\begin{gathered}
\theta_{y, s}=\theta_{y^{-}} \frac{M_{y} L_{v}}{3 E J} \\
\theta_{u, s}=\theta_{u m^{-}} \frac{M_{u} L_{v}}{3 E J} \\
\theta_{u c, s}=\theta_{u, s}+\frac{M_{u} \theta_{y}}{\alpha_{c} M_{y}}
\end{gathered}
$$

where $\theta_{y, s}$ is the spring rotation at yielding, $\theta_{u, s}$ is the spring rotation at ultimate condition and $\theta_{u c, s}$ is the spring rotation corresponding to the complete loss of strength; $\alpha_{c}$ is a percentage of the elastic branch stiffness of the backbone curve and it defines the slope of the degrading branch.

\subsection{Masonry infills}

Masonry infills were modelled adopting equivalent struts, using Truss elements, which follows the constitutive low proposed by Panagiotakos and Fardis [15] (as shown in Figure 4), implemented in the form of a three-linear force-displacement curve through the Hysteretic material of the OpenSees library.

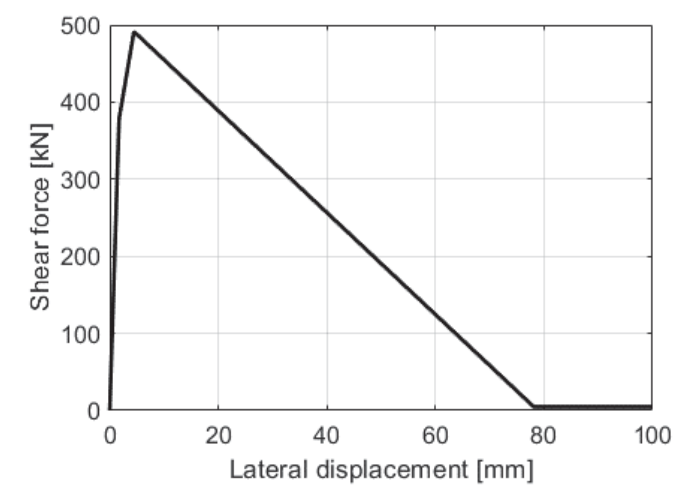

Figure 4: Example of the adopted force-displacement relationship for masonry infills.

The initial behaviour of the infill depends on the initial shear stiffness of the panel, defined as: 


$$
K_{l}=\frac{G_{w} L_{w} t_{w}}{h_{w}}
$$

in which $G_{w}$ is the masonry shear elastic modulus, $L_{w}$ and $h_{w}$ are the effective length and height of the panel, respectively and $t_{w}$ is its thickness. The horizontal force corresponding to the first shear cracking depends on the shear cracking strength $\tau_{c r}$ :

$$
F_{c r}=\tau_{c r} A_{w}=\tau_{c r} L_{w} t_{w}
$$

The stiffness of the second branch of the backbone curve corresponds to the axial stiffness of the equivalent masonry strut, as follows:

$$
K_{2}=\frac{E_{w} b_{w} t_{w}}{d_{w}}
$$

where $E_{w}$ is the masonry elastic modulus, $d_{w}$ is the diagonal length of the infill panel and $b_{w}$ represents the width of the equivalent strut, which was calculated with the formulation proposed in [16]:

$$
\begin{gathered}
b_{w}=d_{w} \cdot 0.175\left(\lambda h_{w}\right)^{-0.4} \\
\lambda=\sqrt[4]{\frac{E_{w} t_{w} \sin (2 \theta)}{4 E_{c} J_{p} h_{w}}}
\end{gathered}
$$

The parameter $\lambda$ defines the relative stiffness of the RC frame and the infill panel, according to the formulation developed in [17], in which $E_{c}$ is the concrete elastic modulus, $J_{p}$ is the moment of inertia of the columns of the surrounding frame and $\theta$ is the inclination angle of the panel with respect to the horizontal. The overstrength ratio, i.e. the ratio between the maximum strength of the masonry strut and the shear cracking strength, is equal to 1.3 , while the stiffness of the degrading branch is $3 \%$ of the initial elastic stiffness, until a residual strength assumed as $1 \%$ of the peak force.

Different equivalent truss geometries were considered; in particular, single- and three-strut models (Figure 5). The first is able to adequately describe the global behaviour of an infilled frame, characterized by an increase in stiffness and resistance compared to a bare frame, but it is not able to simulate the local shear-failure mechanisms in columns due to the interaction with masonry infills. The second one, on the other hand, is capable of taking into account the local interaction phenomena between the frame and the infill panel.

(a)

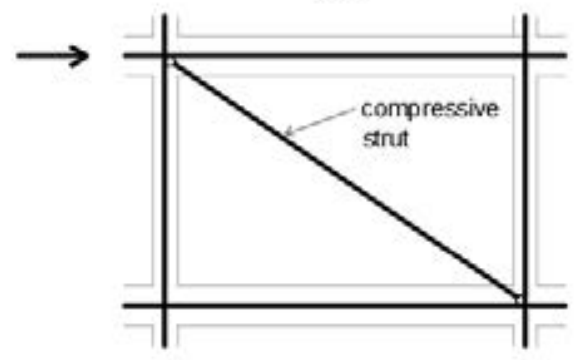

(b)

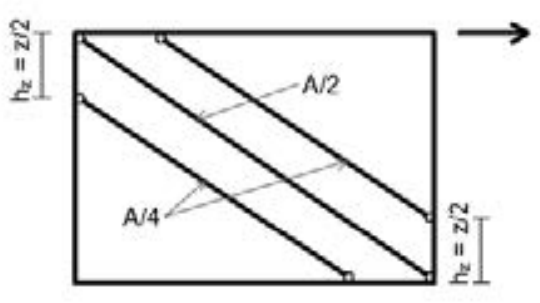

Figure 5: (a) single-strut model; (b) three-strut model.

In the three-strut models the total strut area is distributed among the three truss elements, considering $50 \%$ for the centre element and $25 \%$ for the others. The end node distance of side 
truss elements from a frame node $h_{z}=z / 2$ (see Figure 5) is based on an estimate of the size of the contact area between the infill and the frame, where $z$ is calculated as follows:

$$
z=\frac{\pi}{2 \lambda}
$$

The mechanical characteristics of masonry, such as the elastic modulus, the shear elastic modulus and the shear cracking tension, were defined after [6]. In particular, $E_{w}$ and $G_{w}$ were set to $1495 \mathrm{MPa}$ and $598 \mathrm{MPa}$, respectively, while $\tau_{c r}$ was set to $0.36 \mathrm{MPa}$.

The presence of openings in masonry infills was considered, assuming a percentage of openings $\alpha_{w}=14 \%$, evenly distributed. Therefore, simple relationships based on the definition of reduction coefficients directly applicable to the strut areas were used; in particular, reference was made to the following formulation [18]:

$$
\lambda_{o p}=1-2 \alpha_{w}^{0.54}+\alpha_{w}^{1.14}
$$

\section{ANALYSIS METHODOLOGY}

Non-linear static analyses were carried out using OpenSees software. For each case study structure, pushover analyses were performed both in $\mathrm{X}$ and $\mathrm{Y}$ directions, assuming two different distributions for the horizontal forces: one proportional to the storey masses (uniform distribution), and one dependent on the shape of the first mode of vibration (linear distribution). The outputs of the pushover analyses were then processed using the MATLAB ${ }^{\circledR}$ software, with which a procedure for calculating the displacement demand was also implemented (see Section 4.2).

\subsection{Damage levels for numeric models}

Five levels of damage were defined, deriving them from the EMS-98 macro-seismic scale [19]. Each of these damage states (from DS1 to DS5) was associated to with the achievement of a certain local capacity in terms of displacement. On the basis of the modelling choices made, it was convenient to define the damage to the structural elements as a function of the deformation of the rotational springs that represent the plastic hinges. Damage on the infill panels was defined based on the deformation in the corresponding truss elements. The criteria adopted are as follows:

- DS1 - slight damage: is reached when the first cracks appear in the masonry infills, i.e. when the cracking force of the struts is reached.

- DS2 - moderate damage: this state occurs when either one RC member yields or one truss element reaches its peak strength.

- DS3 - heavy damage: this state occurs when either one of the truss elements reaches its ultimate displacement or one plastic hinge reaches a rotation corresponding to $3 / 4$ of the ultimate rotation capacity.

- DS4 - very heavy: this state occurs when in one of the columns there is a resisting moment degradation of $20 \%$ after the peak resisting moment.

- DS5 - collapse: this state occurs when the total resisting base shear of the structure becomes equal to $20 \%$ of the residual capacity of the bare frames.

In addition to the five damage states described above, a further level of damage (DS5 $5_{\text {shear }}$ ) was considered based on to the achievement of the shear strength in the structural elements (typically in the columns). Shear failure is a fragile failure mechanism which, although not specifically mentioned on the EMS-98 scale, represents very heavy damage. The shear strength 
has been defined according to the current Italian structural design code [20]. Each level of damage was associated to a specific displacement of the control point.

\subsection{Capacity curves}

Sample results for the buildings studied are reported in Figure 6. These plots contrast the different behaviour of bare frames and the infilled frames, the latter being characterized by higher initial stiffness and maximum strength as well as by a relevant loss of strength, after the masonry struts failure. The capacity curve of the entire building was obtained combining infilled and bare frames, as discussed in Section 3.
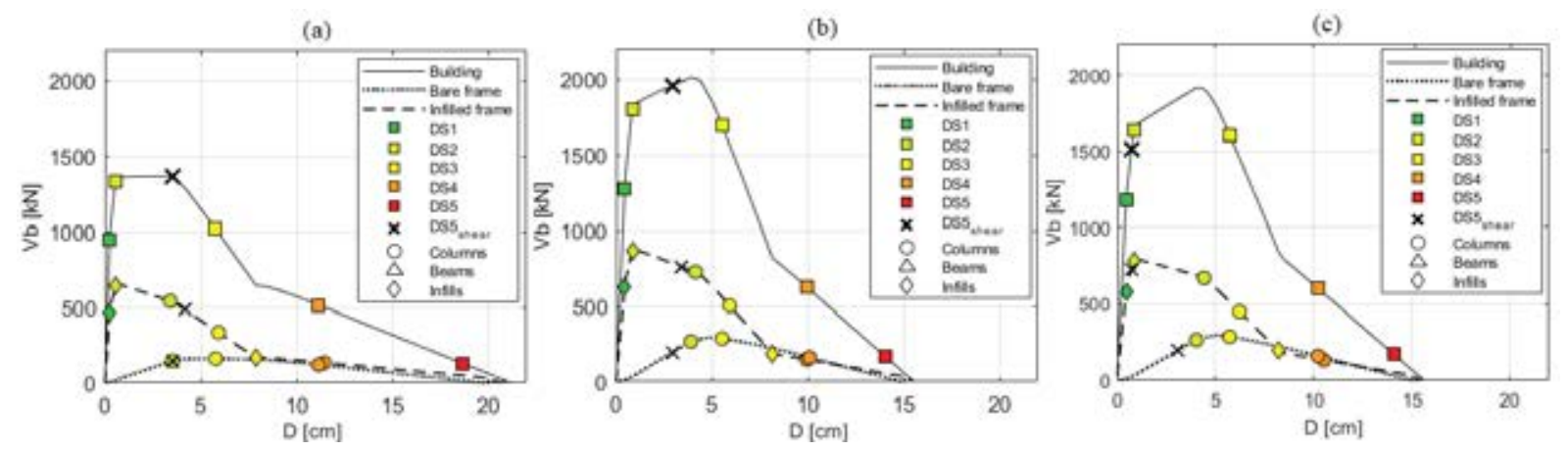

Figure 6: Capacity curves for in the $\mathrm{X}$ direction with mass proportional force distribution for the 2-storey singlestrut model (a); 4-storey with single-strut model (b); 4-storey building, three strut model (c). For further details about geometrical characteristics see Table 1.

The observed collapse mode is predominantly characterized by soft floor mechanisms at the base of buildings. This behaviour is favoured by several factors: the low quality of detailing; the lack of capacity design criteria in design; furthermore, the failure of the infill panels in one floor tends to create a soft storey condition. These factors favour the formation of plastic hinges in columns rather than in beams. The plots in Figure 6 also show the capacity limits associated to the five damage levels under consideration. In the curves shown in Figure 6, it can be observed that the damage level DS2 is characterized by the rupture of the infills rather than by the yielding of the frame elements; conversely DS3 occurs first in the frame. In the 3-strut model (Figure 6-c) it can be observed that the columns shear failure occurs approximately when the peak resistance of the infills is reached, i.e. when the pressure of the panel on the contact area with the frame is maximum. It should be noted that also in the single-strut models shear failures can occur, but these models are not able to simulate the local interaction between the frames and the masonry infills occurring at the ends of columns and beams.

\subsection{Evaluation of the displacement demand}

In pushover analyses the displacement demand on a structure, associated with a certain IM value, such as PGA or spectral acceleration, is computed based on the definition of an equivalent SDOF system and specific $R-\mu-T$ relationships. The present study was based on the IN2 method [21], which is applicable to systems characterized by a significant strength degradation as infilled frame structures. The method requires a preliminary multi-linearization of the pushover curve, respecting the underlying areas equality criteria, as shown in Figure 7. 


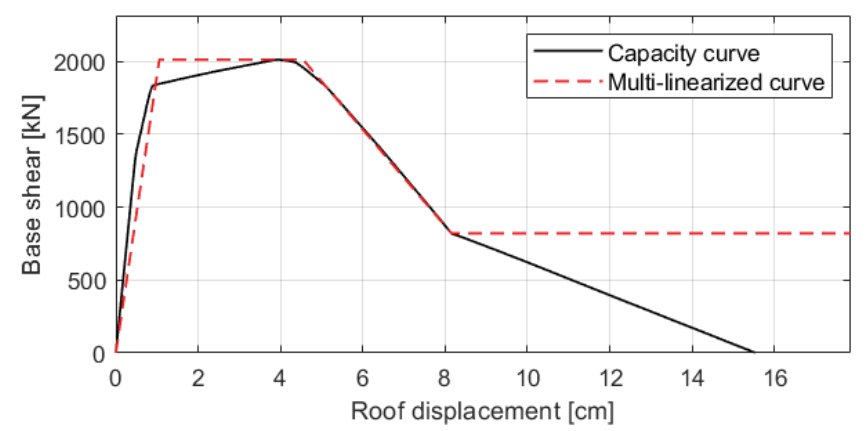

Figure 7: Example of multi-linearization of the 4-storey building capacity curve.

Given an elastic spectrum in terms of acceleration the calculation of the displacement demand first passes through the study of an equivalent SDOF system, and the evaluation of an appropriate inelastic demand spectrum. For the calculation of this latter and of the required ductility, reference was made to the relation $R-\mu-T$ proposed in [22]. This procedure requires an elastic spectrum with a standard Newmark-Hall shape. The elastic spectrum adopted in the present study was defined according to the current Italian structural design code [20], considering a return time of 475 years and assuming a position of the site close to the epicentres of the main shocks that stroke the Emilia area. The IN2 curves in terms of PGA are shown in Figure 8 , for 2 and 4 storey buildings, considering a single strut model for masonry infills.

(a) 2-storey

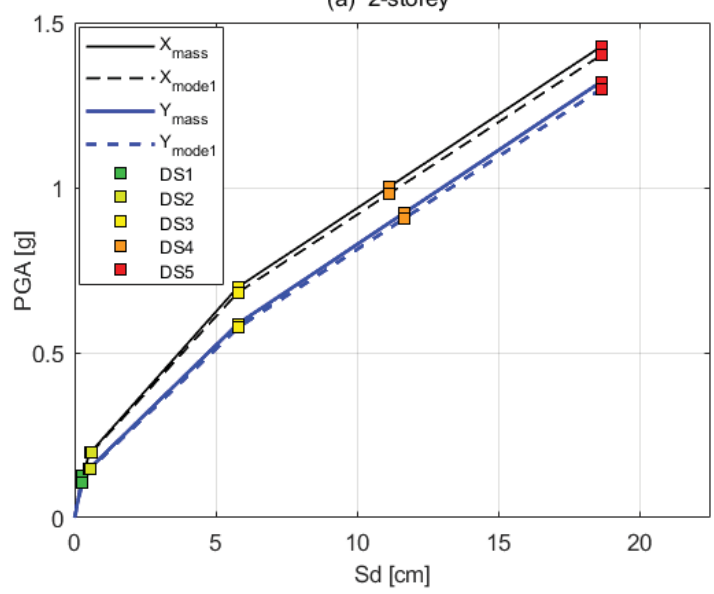

(b) 4-storey

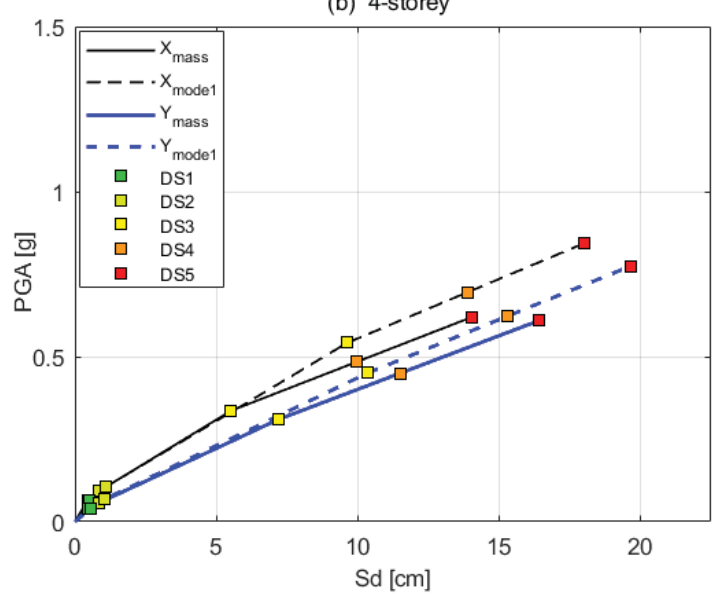

Figure 8: IN2 curves for the 2-storey (a) and 4-storey building (b) single-strut models.

\section{FRAGILITY ANALYSIS}

This section is dedicated to the seismic fragility assessment of the case study buildings. Considering the numerical models presented, a fragility analysis was conducted, with the aim of obtaining fragility curves that relate the probability of reaching the damage levels discussed in Section 4.1 to the values of Peak Ground Acceleration (PGA). To this aim it is necessary to consider the uncertainties that affect the problem under consideration. These are mainly related to: material properties, modelling uncertainties, record-to-record variability and prediction capacity of the analysis method adopted. Random Variables (RV) were used in order to describe these uncertainties. The RVs chosen are (see Table 2): concrete compressive strength $f_{c}$; steel yielding stress $f_{y}$; chord rotation at yielding $\theta_{y}$; chord rotation at ultimate condition $\theta_{u m}$; coefficient $\alpha_{c}$, which determines the slope of the post capping stiffness of RC members; lateral force $F_{\text {inf }}$ and lateral drift $D_{\text {inf }}$ of the infills force-displacement relationship. In particular, different variabilities have been assumed for $F_{\text {inf }}$ and $D_{\text {inf }}$ relatively to the cracking point and 
the peak point of the infills behaviour curve. The variables described above influence the behaviour of the building, in particular, affecting the capacity curve. However, the $R-\mu-T$ relation used to determine the inelastic spectra in the calculation of the displacement demand, provides an average value of the required ductility. Therefore, a certain variability was assumed also for the ductility demand [22], this represents both the uncertainty on the prediction provided by the adopted analysis method and record-to-record variability. A log-normal distribution has been assumed for all RVs and the corresponding coefficients of variation are shown in Table 2 . The coefficient of variation for concrete compressive strength was evaluated in order to fall within the limit values set for the concrete acceptance criteria, while that relating to the coefficient $\alpha_{c}$ was defined in order to obtain a median value comparable with the formulation reported in [23], and extreme values contained within the range tested in [24].

For each building model, given a set of random values of the RVs, defined a loading direction and a distribution of forces it is possible to compute a capacity curve, which can then be used to find scaling factor for the elastic response spectrum that leads to a displacement demand equal to the capacity associated to a certain DS. The PGA of the so obtained scaled spectrum represents a measure of the structural capacity for the DS under consideration. By repeating this procedure for more samples of the RVs is possible to obtain a sample of the PGA capacity values associated to a certain DS, the cumulative probability distribution of these values represents, the fragility curve relative to the considered damage level. However, such a procedure is computationally inefficient because it requires a large number of samples. Therefore, Response Surface (RS) models were introduced in order to find empirical relationships between the structural capacities for each of the DSs under consideration and the values of the RV. A RS is a statistical regression model that interpolates, within a certain domain, the values of a response variable - PGA capacity for a certain DS in this case - as a function of a set of independent variables.

\begin{tabular}{|c|c|c|c|}
\hline RV & Distribution & CoV & Reference \\
\hline$f_{c}$ & Log-normal & 0.20 & \\
$f_{y}$ & Log-normal & 0.08 & {$[11]$} \\
$\theta_{\mathrm{y}}$ & Log-normal & 0.331 & {$[5]$} \\
$\theta_{\mathrm{um}}$ & Log-normal & 0.54 & {$[23]$} \\
$\alpha_{\mathrm{c}}$ & Log-normal & 0.55 & \\
$\mathrm{Finf}_{\mathrm{inf}}=\left[\mathrm{Fcr} ; \mathrm{F}_{\max }\right]$ & Log-normal & {$[0.3 ; 0.3]$} & {$[5]$} \\
$\mathrm{D}_{\text {inf }}=\left[\mathrm{D} \mathrm{cr} ; \mathrm{D}_{\max }\right]$ & Log-normal & {$[0.3 ; 0.7]$} & {$[5]$} \\
\hline$\mu($ ductility $)$ & Log-normal & 0.70 & {$[22]$} \\
\hline
\end{tabular}

Table 2: Random Variables and uncertainty parameters.

In order to obtain data for fitting the RS models, the Central Composite Design (CCD) criterion was used in order to define a set of values of the RVs to be used for the pushover analyses. Since, as discussed later, the ductility demand was not considered in the RS models, the number of RVs is 7 , which according to CCD correspond to $2^{7}+2 \cdot 7+1=143$ combinations of the RV values to be used for pushover analyses. These are carried out for each model, for each direction and for each distribution of forces. The form of RS model adopted for each structure, for the $i$-th DS associated to a loading direction and a force distribution is:

$$
\begin{gathered}
\ln \left(P G A_{D S \geq D S i}\right)=b_{0}+b_{1} \ln \left(f_{c}\right)+b_{2} \ln \left(f_{y}\right)+b_{3} \ln \left(\theta_{y}\right)+b_{4} \ln \left(\theta_{u m}\right)+b_{5} \ln \left(\alpha_{c}\right)+b_{6} \ln \left(F_{\text {inf }}\right)+ \\
+b_{7} \ln \left(D_{\text {inf }}\right)+\varepsilon
\end{gathered}
$$

where $b_{0}$ to $b_{7}$ are unknown regression coefficients, and $\varepsilon$ in a normal error term. Their values were estimated by means of linear regression. The standard deviation of the error term was the 
augmented considering the uncertainty on the ductility demand [22]. Since a log-normal distribution for the RVs was assumed, $\ln \left(P G A_{D S} \geq D S i\right)$ is a linear combination of normally distributed variables and therefore assumes a normal distribution which is fully defined by its mean value and standard deviation. The cumulative distribution function for $\ln \left(P G A_{D S} \geq D S i\right)$ represents the fragility curve for the $i$-th DS. As mentioned above, fragility curves are obtained for the different main directions of the building and for the different horizontal force profiles (Figure 9).

Fragility curves for the $\mathrm{X}$ and $\mathrm{Y}$ directions of each building (Figure 9-a) were obtained by considering the highest probability value (worst case) between the curves associated to the two different lateral load distributions. In order to provide a global assessment of the building's seismic vulnerability, direction-independent fragility curves were also evaluated; these curves were obtained as the average exceedance probability for generic DS for the two different directions (Figure 10). Considering the worst case between the $\mathrm{X}$ and $\mathrm{Y}$ directions would in fact lead to a systematic overestimation of the building's vulnerability. The fragility curves obtained for 2 and 4-storey buildings show that the latter is more vulnerable than the former, with differences in the probability of damage higher that $30 \%$, in particular for the DS3, DS4, DS5 and DS5 $5_{\text {shear }}$ in the PGA range between $0.2 \mathrm{~g}$ and $0.6 \mathrm{~g}$.

(a)

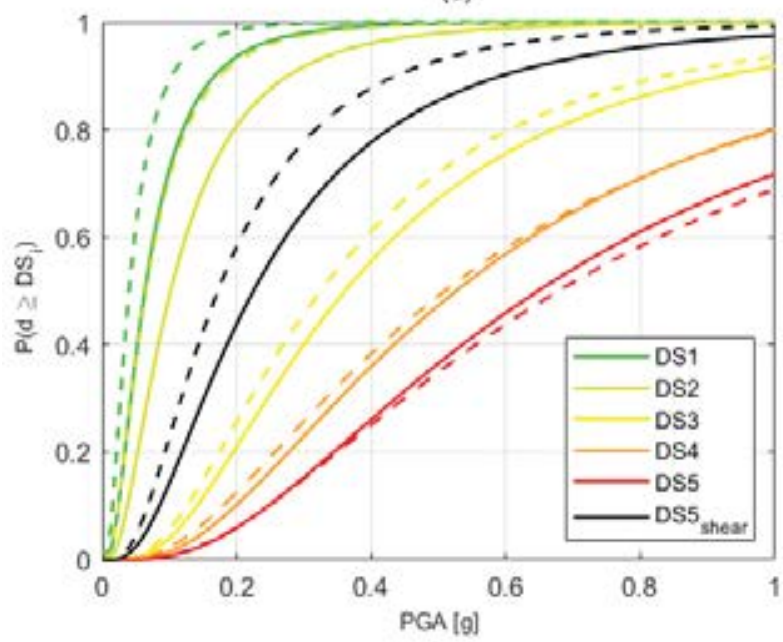

(b)

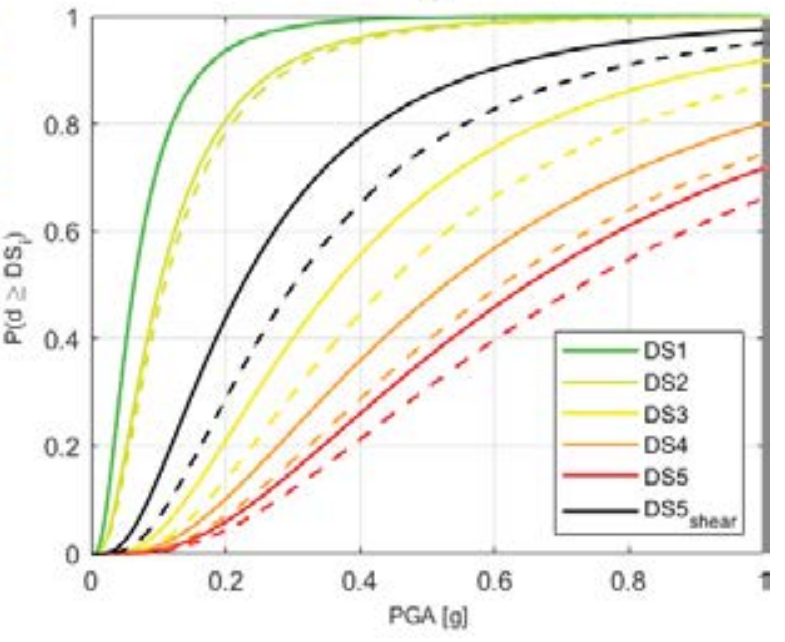

Figure 9: Fragility curves for the 4-storey building: (a) X (solid line) and Y direction (dashed line); (b) force distribution proportional to storey masses (solid line) and to the first mode (dashed line). 
(a)

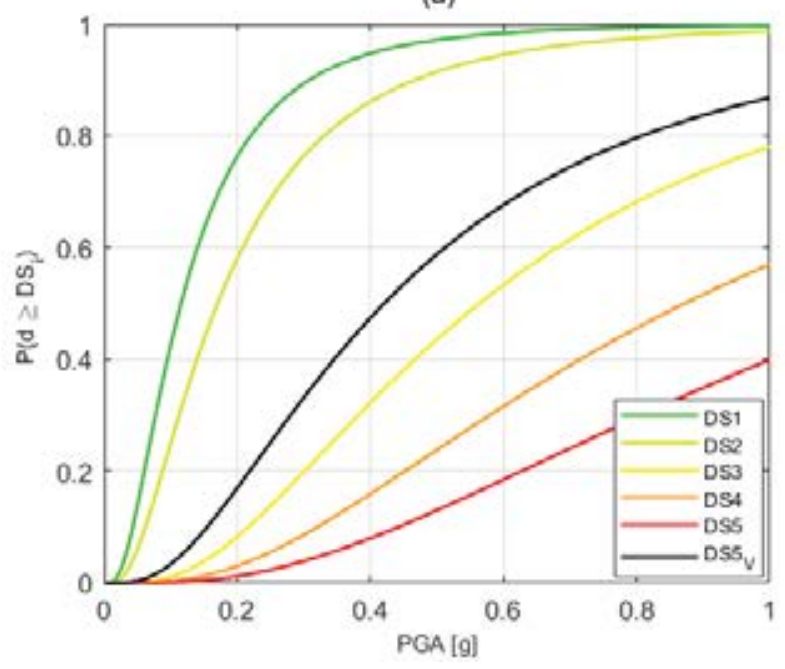

(b)

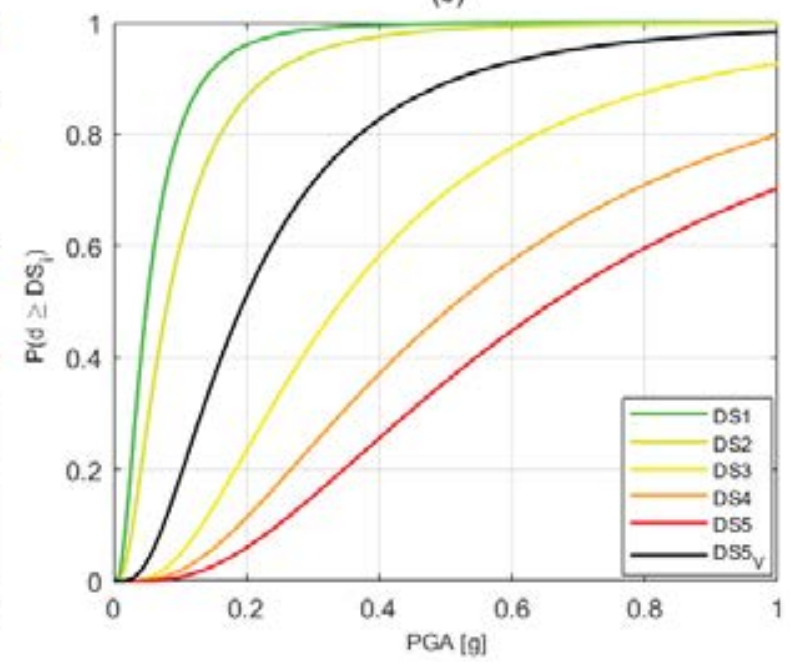

Figure 10: Global capacity curves (single strut model): 2-storey (a) and 4-storey building (b).

The fragility curves for the 4-storey building modelled with 3 equivalent struts are shown in Figure 11. For the frame members a flexural behaviour similar to the case of the single strut model was observed, however, with this model, an anticipated shear failure at the ends of the columns can be triggered, due to the local interaction between the infill panel and the surrounding frame. The fragility curve associated with shear failure is very close to the curve associated with DS2, corresponding to the first condition to occur between the infill peak strength and yielding of the frame elements. In the three-strut model the shear failure of the columns tends, therefore, to occur at the maximum strength in the masonry struts and to anticipate the columns yielding.

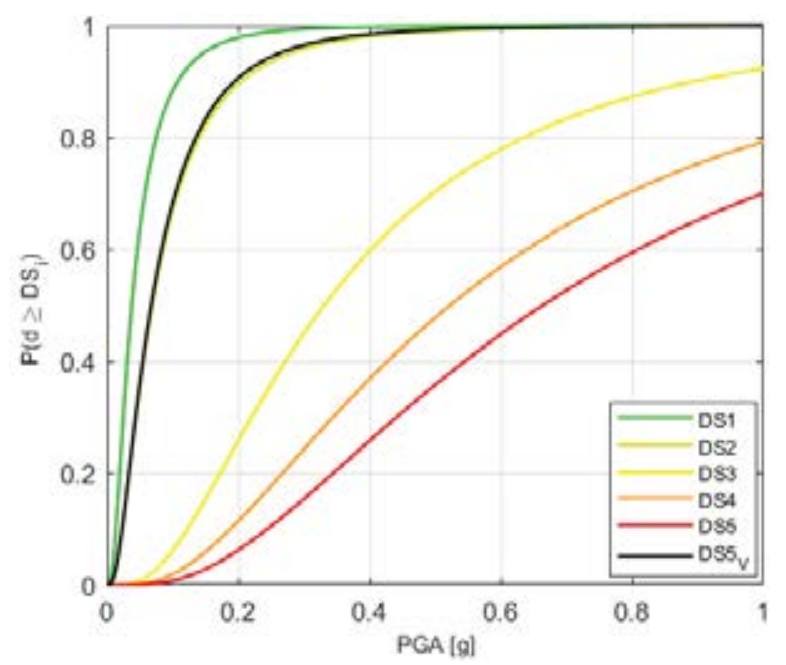

Figure 11: Global capacity curves for the 4-storey building (three strut model).

\section{CONCLUSIONS}

With this work we have contributed to the seismic vulnerability assessment of RC frames with masonry infills. Starting from a study on the characteristics of the existing building stock in the Emilia area, case study buildings were defined, then modelled with finite elements considering the contribution of masonry infills. Non-linear static analyses were carried out on 
the obtained models and the capacity in terms of PGA associated with different DSs was evaluated. Fragility curves were finally developed for the examined buildings using RS models. Different infills models were considered, in order to simulate the fragile shear failure in the columns. However, the three-strut modelling used here, while capturing the local interaction described, are not able to adequately describe the behaviour of the structure after the shear failure has been detected. Fragility curves have also been presented for shear failure, but in these terms, more work is needed.

\section{ACKNOWLEDGEMENTS}

The financial support of the Italian Civil Protection Department, DPC-RELUIS 19-21 research project, Workpackage WP17, is gratefully acknowledged.

\section{REFERENCES}

[1] Penna, A., Morandi, P., Rota, M. et al. Performance of masonry buildings during the Emilia 2012 earthquake. Bull Earthquake Eng 12, 2255-2273 (2014).

[2] Buratti, N., Minghini, F., Ongaretto, E., Savoia, M., Tullini, N., Empirical seismic fragility for the precast RC industrial buildings damaged by the 2012 Emilia (Italy) earthquakes. Earthquake Engineering and Structural Dynamics, 2017, 46(14), pp. $2317-$ 2335 .

[3] Savoia, M., Buratti, N., Vincenzi, L., Damage and collapses in industrial precast buildings after the 2012 Emilia earthquake. Engineering Structures, 2017, 137, pp. 162-180.

[4] Ricci P., De Risi M.T., Verderame G.M., Manfredi G., (2013). Influence of infill distribution and design typology on seismic performance of low- and mid-rise RC buildings. Bulletin of Earthquake Engineering, DOI 10.1007/s10518-013-9453-4.

[5] Verderame, G., Ricci, P., De Luca, F., Del Gaudio, C., \& De Risi, M. T. (2014). Damage scenarios for RC buildings during the 2012 Emilia (Italy) earthquake. Soil Dynamics and Earthquake Engineering, 66, 385-400.

[6] G. Uva, D. Raffaele, F. Porco, A. Fiore, On the role of equivalent strut models in the seismic assessment of infilled RC buildings. Engineering Structures 42 (2012) 83-94.

[7] A.F. Mohammad, M. Faggella, R. Gigliotti, E. Spacone, Seismic performance of older $\mathrm{R} / \mathrm{C}$ frame structures accounting for infills-induced shear failure of columns. Engineering Structures 122 (2016) 1-13.

[8] Daniele Perrone, Marianovella Leone, Maria Antonietta Aiello, Non-linear behaviour of masonry infilled RC frames: Influence of masonry mechanical properties. Engineering Structures 150 (2017) 875-891.

[9] Buratti, N., Ferracuti, B., Savoia, M., Response Surface with random factors for seismic fragility of reinforced concrete frames. Structural Safety, 2010, 32(1), pp. 42-51.

[10] Decreto Ministeriale 16 giugno 1976 - Norme tecniche per la esecuzione delle opere in cemento armato normale e precompresso e per le strutture metalliche. 
[11] Verderame GM, Stella A., Cosenza E. (2001). Le proprietà meccaniche degli acciai impiegati nelle strutture in c.a. realizzate negli anni 60'. X Convegno nazionale "L'Ingegneria Sismica in Italia”, Potenza-Matera, 9-13 settembre.

[12] McKenna, F., Fenves, G.L., Scott, M.H. (2004). OpenSees: Open System for Earthquake Engineering Simulation. Pacific Earthquake Engineering Research Center. University of California, Berkeley, CA, USA. http://opensees.berkeley.edu.

[13] Ibarra, L. F., Medina, R. A., and Krawinkler, H. (2005). Hysteretic models that incorporate strength and stiffness deterioration, Earthquake Engineering and Structural Dynamics, Vol. 34, 12, pp. 1489-1511.

[14] EN 1998-3:2005, Eurocode 8 - Design of structures for earthquake resistance - Part 3: Assessment and retrofitting of buildings.

[15] Panagiotakos, T. B., \& Fardis, M. N., (1996): "Seismic Response of Infilled R/C Frames Structures", Proc. of the 11th World Conference on Earthquake Engineering, Mexico, paper 225.

[16] Klingner, R. E., \& Bertero, V. V., (1976): "Infilled frames in earthquake-resistant construction", Report EERC 76-32, Earthquake Engineering Research Center.

[17] Stafford Smith, B., (1966): "Behavior of Square Infilled Frames", Journal of the Structural Division, Vol. 92, n. ST1, pp. 381-403.

[18] P.G. Asteris, I.P. Giannopoulos, C.Z. Chrysostomou, Modeling of Infilled Frames With Openings. The Open Construction and Building Technology Journal, 2012, 6, (Suppl 1M6) 81-91.

[19] Grünthal, G. ed. 1998. 'European Macroseismic Scale 1998 (EMS-98)', Cahiers du Centre Européen de Géodynamique et de Séismologie 15, Helfent-Betrange (Luxembourg).

[20] Decreto Ministeriale 17-01-2018: Norme tecniche per le costruzioni (GU Serie Generale n.42 del 20-02-2018 - Suppl. Ordinario n. 8).

[21] Dolšek, M., Fajfar, P. (2005). Simplified non-linear seismic analysis of infilled reinforced concrete frames. Earthquake Engineering and Structural Dynamics, 34(1), 49-66.

[22] Dolšek, M., Fajfar, P. (2004). Inelastic spectra for infilled reinforced concrete frames. Earthquake Engineering and Structural Dynamics, 33(15), 1395-1416.

[23] Haselton, C.B., A.B. Liel, S. Taylor Lange, and G.G. Deierlein (2008). Beam-Column Element Model Calibrated for Predicting Flexural Response Leading to Global Collapse of RC Frame Buildings, PEER Report 2007/03, Pacific Engineering Research Center, University of California, Berkeley, California.

[24] Ibarra, L. F., and Krawinkler, H. (2005). Global collapse of frame structures under seismic excitations, Technical Report 152, The John A. Blume Earthquake Engineering Research Center, Department of Civil Engineering, Stanford University, Stanford, CA. 